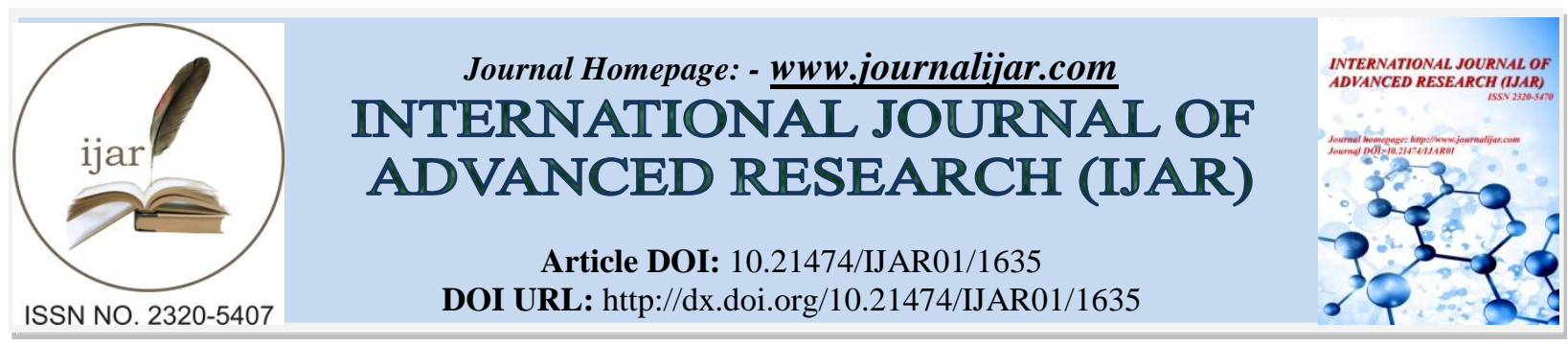

RESEARCH ARTICLE

\title{
PHYSICOCHEMICAL CHARACTERIZATION AND BIOLOGICAL ACTIVITY OF A DIHYDROFLAVONOL FROM SUDANESE ALBIZIA AMARA(ROXB.)B.BIOVIN LEAVES.
}

\author{
Abdel Karim $\mathbf{M}^{1, *}$ and Munjed $\mathbf{S}^{2}$ \\ 1. Sudan University of Science and Technology, Faculty of Science, Dept. of Chemistry \\ 2. University of Bahri, College of Industrial and Applied Chemistry, Dept. of Chemistry
}

\begin{abstract}
Manuscript Info
Manuscript History

Received: 12 July 2016

Final Accepted: 12 August 2016

Published: September 2016

Key words:-

Albizia amara, isolation,

dihydroflavonol, biological activity

\section{Abstract}

A dihydroflavonol was isolated from the leaves of Sudanese Albizia amara. The isolate was purified by different chromatographic techniques and identified via a combination of spectral tools (IR, UV, ${ }^{1}$ HNMR and mass spectroscopy). The isolated compound was screened for its antimicrobial activity against six standard human pathogens (Bacillus subtilis, Staphylococcus aureus, Pseudomonas aeruginosa, Escherichia coli, Aspergillas niger, candida albicans), and promising results were obtained.
\end{abstract}

Copy Right, IJAR, 2016,. All rights reserved.

\section{Introduction:-}

Since, ancient times nature has been an important source of medicinal agents and a large number of natural products have been identified and developed from natural sources based on their use in traditional medicine(Bhaskar and Balakrishnan,2009). Numerous medicinal plants are of global interest today because of their therapeutic and economic significance(Kokila et.al.,2013).

The genus Albizia comprises approximately 150 species, mostly trees and shrubs native to tropical and subtropical regions of Asia and Africa(King and Young,1999). The current literature revealed that some plants belonging to genus Albizia have great medicinal values(Hong et.al.,2005). Recently, an antitumour saponin- julibroside -was isolated from the stem bark of A. julibrissin(Ravishankar and Shukla,2007). It is also reported that A. lebbeck has antiseptic, antidysentric and anti-tubercular activities(Khan et.al.,2010).

Albizia amara ( Leguminaceae)is a deciduous tree, often rounded or spreading crown, reaching $10 \mathrm{~m}$ in height but often smaller. Leaf and flowers of this plant show antiinflammatory activity and are usually used for boils and ulcers(Kumar et.al.,2008). Seeds showed astringent, antidiarrhoeal and antibacterial effects , whereas different plant extracts showed DNA binding properties and antibacterial activity. They also inhibited platelet aggregation and human lymphocyte transformation beside antiinflammatory and cytotoxic activity(Gasper and Nshimo,1988). The oil from the seeds is said to cure leprosy and leucoderma(Pal et al.,2010). In traditional medicine the roots are chewed and applied to an eye infection of cattle.Fruits are used traditionally as an emetic and for treating coughs and malaria. Saponins were extracted from the roots and leaves. Tannins and gums were extracted from the bark.Gum is used against ulcers; fruits are said to cure malaria and coughs. Bark stem decoction taken three times per day serves as an emetic to induce vomiting and to treat malaria(Dharani,2002). Leaves are said to be used in the treatment of wounds(Mukhtar and Ghori,2012).

Corresponding Author:- Abdel Karim M.

Address:- Sudan University of Science and Technology, Faculty of Science, Dept. of Chemistry. 
In continuation of our interest in bio-constituents of plant species used by local healers in Sudan, we planned to investigate the flavonoids of Albizia amara which is used traditionally to treat an array of human disorders.

\section{Materials and Methods:- Materials:-}

The UV spectra were recorded on a Shimadzu 1601 Spectrophotometer and UV lamp was used for localization of fluorescent spots on TLC and PC. The IR spectrum was recorded as KBr disc, using Perkin-Elmer, FTIR 1600Jasco. Nuclear Magnetic Resonance spectrum was run on a Bruker AM 500 MHZ NMR Spectrophotometer. The mass spectrum was recorded by direct probe EIMS using a Shimadzu QP-class-500 spectrometer.

\section{Plant material:-}

The leaves of Albizia amara were collected in April 2015 from "Maleet" (western Sudan) The plant was identified and kindly authenticated by the Dept. of Botany, University of Khartoum.

\section{Methods:-}

\section{Isolation of flavonoids:-}

Powdered shade- dried leaves $(1 \mathrm{~kg})$ of Albizia amara were macerated with $95 \%$ ethanol at room temperature for 48 hours. The crude extract was suspended in water and partitioned with organic solvents in order of increasing polarity: petroleum ether, chloroform, ethyl acetate and n-butanol. The n-butanol fraction was rich in phenolics. It was dissolved in methanol and applied to Whatman paper (No. $3 \mathrm{~mm}-46 \mathrm{x} 57 \mathrm{~cm})$. The bands were irrigated with BAW (n-butanol- acetic acid-water; 4:1:5;v:v:v). The developed chromatograms were air-dried and examined under both visible and UV light $(\kappa 366,245 \mathrm{~nm})$. The chromatograms were exposed to ammonia vapour for about $2-3$ seconds and immediately re-examined to observe possible changes that may eventually appear in colour or fluorescence under a long wavelength UV lamp. The equivalent bands from each paper were then cut out, combined and cut into small strips and slurred with methanol. After several hours of contact with occasional shaking, the liquid was evaporated in vaсиo to dryness. In this way a flavonoid-compound I was isolated in chromatographically pure form as yellow amorphous powder.

\section{Antimicrobial assay:-}

Compound I was screened for antimicrobial activity against six standard human pathogens (Bacillus subtilis, Staphylococcus aureus, Pseudomonas aeruginosa, Escherichia coli, Aspergillas niger and Candida albicans).

\section{Preparation of bacterial suspensions:-}

One $\mathrm{ml}$ aliquots of a 24 hours broth culture of the test organisms were aseptically distributed onto nutrient agar slopes and incubated at $37^{\circ} \mathrm{C}$ for 24 hours. The bacterial growth was harvested and washed off with $100 \mathrm{ml}$ sterile normal saline, to produce a suspension containing about $10^{8}-10^{9}$ C.F.U/ $\mathrm{ml}$. The suspension was stored in the refrigerator at $4^{\circ} \mathrm{C}$ till used. The average number of viable organisms per $\mathrm{ml}$ of the stock suspension was determined by means of the surface viable counting technique(Wikler,2007). Serial dilutions of the stock suspension were made in sterile normal saline solution and $(0.02 \mathrm{ml})$ volumes of the appropriate dilution were transferred by micro pipette onto the surface of dried nutrient agar plates. The plates were allowed to stand for two hours at room temperature for the drops to dry and then incubated at $37^{\circ} \mathrm{C}$ for 24 hours. After incubation, the number of developed colonies in each drop was counted. The average number of colonies per drop $(0.02 \mathrm{ml})$ was multiplied by 50 and by the dilution factor to give the viable count of the stock suspension, expressed as the number of colony forming units per ml suspension.

Each time a fresh stock suspension was prepared. All the above experimental conditions were maintained constant so that suspensions with very close viable counts would be obtained.

\section{Preparation of fungal suspension:-}

The fungal cultures were maintained on dextrose agar, incubated at $25{ }^{\circ} \mathrm{C}$ for 4 days. The fungal growth was harvested and washed with sterile normal saline and finally suspended in $(100 \mathrm{ml})$ of sterile normal saline, and the suspensions were stored in the refrigerator until used. 


\section{Testing of antibacterial activity:-}

The cup plate agar diffusion assay was adopted to screen the antibacterial activity. The experiment was carried out according to the National Committee for Clinical Laboratory Standards Guidelines(Wikler,2007).. Bacterial suspension was diluted with sterile physiological solution to $10 \mathrm{cfu} / \mathrm{ml}$ (turbidity $=$ McFarland standard 0.5 ). One hundred microliter of bacterial suspension were swabbed uniformly on surface of MHA and the inoculum was allowed to dry for 5 minutes. Sterilized filter paper discs (Whatman No.1, $6 \mathrm{~mm}$ in diameter) were placed on the surface of the MHA and soaked with $(20 \mu \mathrm{l})$ of test solution. The plates were incubated at $37{ }^{\circ} \mathrm{C}$ for $24 \mathrm{~h}$ in the inverted position. The diameters $(\mathrm{mm})$ of the inhibition zones were measured in triplicates and averaged.

\section{Testing of antifungal activity:-}

The above mentioned method was adopted for antifungal activity, but instead of agar, dextrose agar was used. Samples were used here by the same concentrations used above.

\section{Results and Discussion:-}

Identification of compound I:-

Compound I was isolated as yellow amorphous powder from n-butanol fraction of Albizza amara leaves. The structure of this flavonoid was deduced on the basis of its spectral data (IR, UV, ${ }^{1} \mathrm{HNMR}$ and MS).

The IR (KBr) spectrum of compound I (Fig 1) showed : v (KBr)615,744 (C-H, bending , Ar.), 1024 (C-O), 14561558(C=C, Ar.), 1650(C=O), 2923(C-H, aliph.) and $3382 \mathrm{~cm}^{-1}(\mathrm{OH})$.

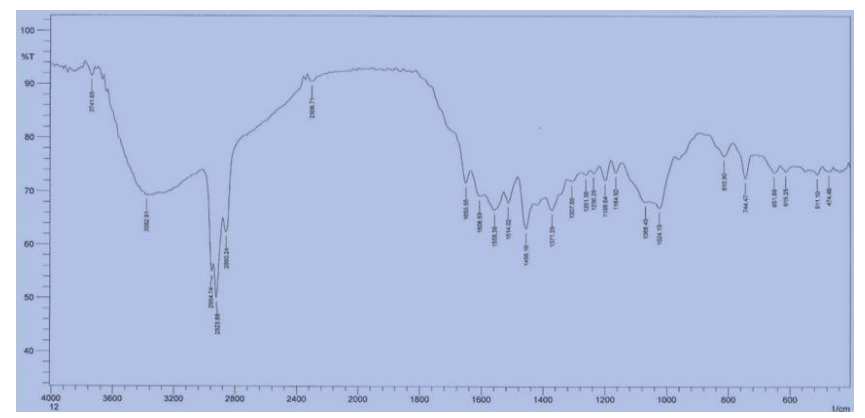

Fig. 1:- IR spectrum of compound I

In the UV, compound I absorbs at $\lambda_{\max }(\mathrm{MeOH}) 267 \mathrm{~nm}$ (Fig.2). No shoulder characteristic of isoflavones (Mabry and Markham ,1975) appeared in the range: $300-340 \mathrm{~nm}$.

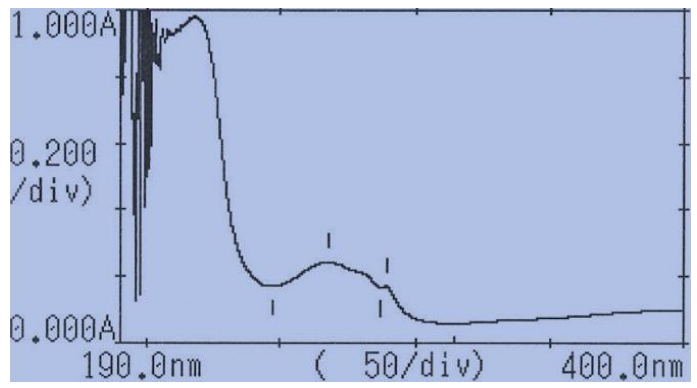

Fig.2:- UV spectrum of compound I

The sodium methoxide spectrum (Fig.3) revealed a bathochromic shift with decrease in intensity diagnostic of a 3OH function(Mabry and Markham,1975). Thus compound I is a dihydroflavonol. 


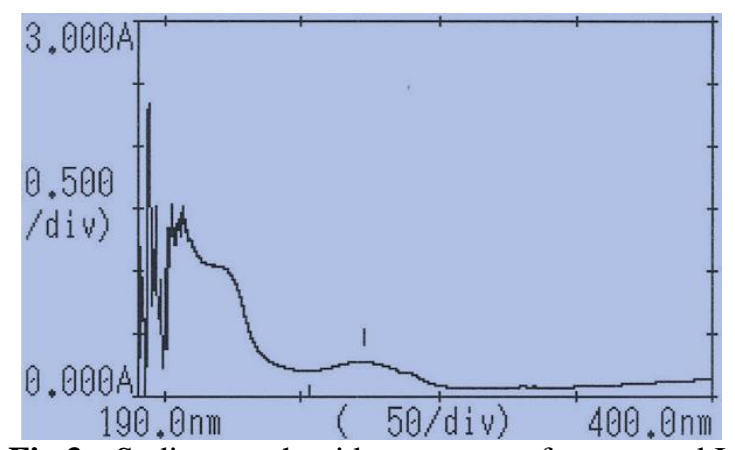

Fig.3:- Sodium methoxide spectrum of compound I

No detectable bathochromic shifts were observed in the sodium acetate and boric acid spectra (Figures: 4 and 5). This clearly indicates absence of a 7-OH as well as catechol systems. However, the aluminium chloride spectrum (Fig. 6) gave a bathochromic shift diagnostic of a 3-OH function(Mabry and Markham ,1975).

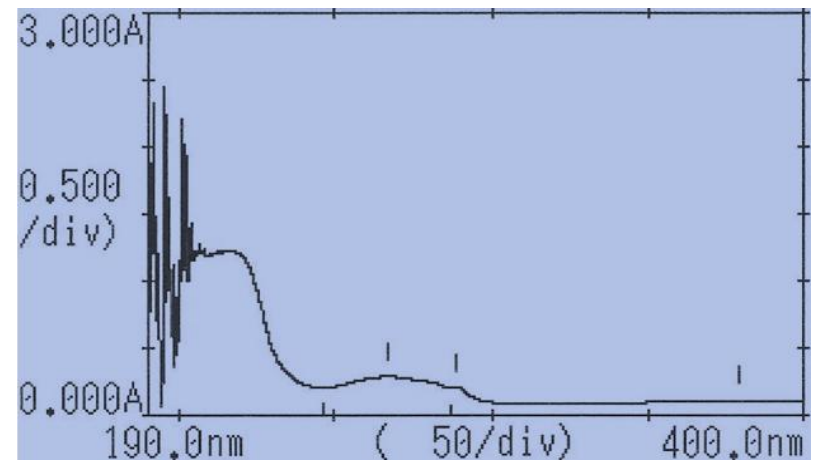

Fig. 4:- Sodium acetate spectrum of compound I

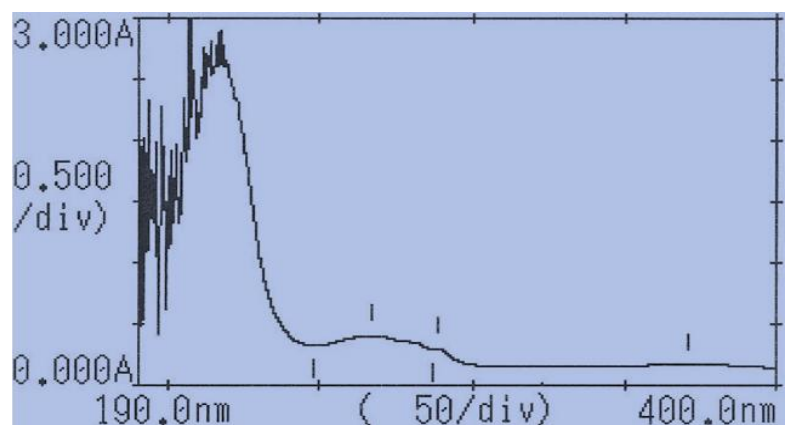

Fig.5:- Boric acid spectrum of compound I

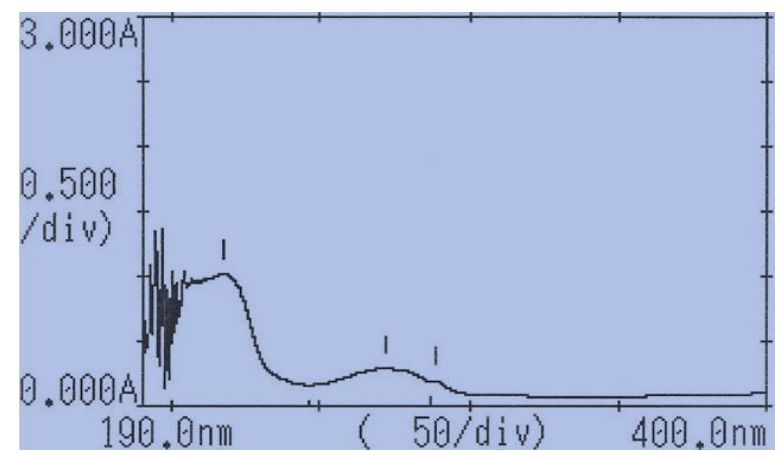

Fig.6:- Aluminium chloride spectrum of compound I 
The ${ }^{1}$ HNMR spectrum (Fig.7) showed two singlets at $\delta 0.85$ and $\delta 1.25$ each integrating for 3 protons assigned for two methyl groups. The $\mathrm{C}_{2}$ proton resonated at $\delta 3.00 \mathrm{ppm}$ due to the deshielding influence of the neighbouring oxygen atom. The signal at $\delta 1.90(3 \mathrm{H})$ was attributed to an acetyl function, while the resonance at $\delta 3.80(3 \mathrm{H})$ accounts for a methoxyl function. The multiplet at $\delta 3.30-3.70 \mathrm{ppm}$ accounts for sugar protons. The signals at $\delta 6.109(1 \mathrm{H})$ and $\delta 6.30(1 \mathrm{H})$ were assigned for $\mathrm{C}_{6}$ and $\mathrm{C}_{8}$ protons respectively. The latter usually resonates at lower field relative to the former due to the deshielding effect of the neighbouring oxygen atom .The aromatic protons appeared as multiplet at $\delta 6.95-7.80 \mathrm{ppm}$. The mass spectrum gave $\mathrm{m} / \mathrm{z} 340$ for $\mathrm{M}+$ (aglycone).Glycosidic flavonoids rarely afford discernible molecular ions for the glycoside ,but they do afford a distinguished peak for aglycone-usually base peak(Mabry and Markham ,1975; Cuyckens and Claeys,2004).

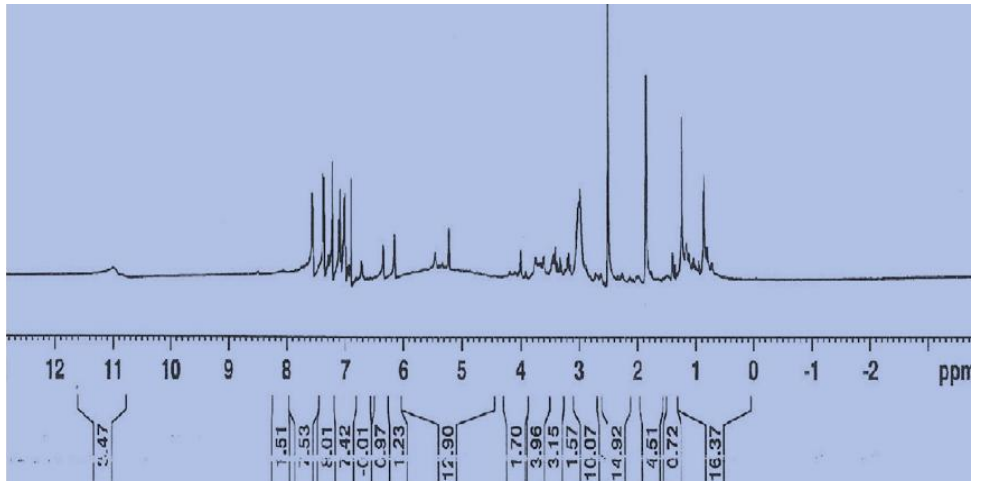

Fig. 7:- 1HNMR spectrum of compound I

The substitution pattern of A ring was deduced from (i) no downfield signal (around $8.00 \mathrm{ppm}$ ) was observed for $\mathrm{C}_{5}$ proton and (ii) the NMR spectrum revealed a 3 proton signal for A ring protons and (iii) the retro Diels-Alder fission (Scheme I) gave m/z 150 for intact A ring. The assignment of two methyl and an acetyl function for B ring was based on the retro Diels-Alder cleavage which revealed a signal at m/z190 for intact B ring. Comparison of the above cumulative data with data published in literature resulted in the following partial structure for compound I:<smiles>COc1cccc2c1C(=O)C(O)C(C1CC3(C)CCOCC(C)(C3)C1C)O2</smiles><smiles>COc1cccc2c1C(=O)C(O)C(C1CC3CCC(C)(C1)C3(C)C)O2</smiles><smiles>COc1cccc(OC)c1CO</smiles>

Scheme I:- Retro Diels -Alder fission of compound I 


\section{Antimicrobial activity:-}

The mean diameters of inhibition zones (MDIZ) and the minimum inhibitory concentration (MIC) produced by compound I on standard microorganisms are presented in Table (1). The results were interpreted in commonly used terms : (<) $9 \mathrm{~mm}$ : inactive ; 9-12 $\mathrm{mm}$ : partially active ; $13-18 \mathrm{~mm}$ : active; (>) $18 \mathrm{~mm}$ : very active.

Table 1:- The antibacterial activity of compound I

\begin{tabular}{|l|l|l|l|l|l|l|}
\hline \multirow{4}{*}{ Sample } & \multicolumn{3}{|c|}{ Inhibition zone diameter (mm / mg sample) } \\
\cline { 2 - 7 } & \multicolumn{3}{|c|}{ Antibacterial activity } & \multicolumn{2}{c|}{ Antifungal activity } \\
\cline { 2 - 7 } & $\begin{array}{l}\text { Bs. } \\
(\mathrm{G}+)\end{array}$ & $\begin{array}{l}\text { Sa. } \\
(\mathrm{G}+)\end{array}$ & $\begin{array}{l}\text { Ec. } \\
(\mathrm{G}-)\end{array}$ & $\begin{array}{l}\text { Pa. } \\
(\mathrm{G}-)\end{array}$ & Ca. & An. \\
\hline Control(Methanol) & 00 & 00 & 00 & 00 & 00 & 00 \\
\hline $100 \mathrm{mg} / \mathrm{ml}$ & 15 & 15 & 13 & 13 & 15 & 15 \\
\hline $50 \mathrm{mg} / \mathrm{ml}$ & 14 & 14 & 12 & 12 & 14 & 15 \\
\hline
\end{tabular}

Sa.: Staphylococcus aureus

Ec.: Escherichia coli

Pa.: Pseudomonas aeruginosa

Bs.: Bacillus subtilis

An.: Aspergillus niger

Ca.: Candida albicans

At a concentration of $100 \mathrm{mg} / \mathrm{ml}$,compound I showed antibacterial and antifungal responses against all test organisms. However at $50 \mathrm{mg} / \mathrm{ml}$ it was active against the bacterial strains Bacillus subtilis and Staphylococcus aureus and the fungal species : Candida albicans and Aspergillas niger and partially active against other test organisms.

\section{References:-}

1. Bhaskar, H.V., Balakrishnan N.(2009), India.Int.J. Health Res, $2,123$.

2. Cuyckens, F., Claeys, M.(2004), Journal of Mass Spectrometry, 39, 1.

3. Dharani, N., "Field Guide to Common Trees and Shrubs of East Africa", Struik Publishers, Cape Town, South Africa (2002).

4. Gasper, B., Nshimo, C. M.(1988), Eur.J., 89, 240

5. Hong, L., Yong, T.W., Ying, Z.Y., Rong, C.J., Zhong, T.G.(2005), Bioorganic \& Medicinal Chemistry Letters, 15, 4493

6. Houghton, P.J.(1995), The Journal of Alternative and Complementary Medicine, 2,131.

7. Kokila, K., Priyadharshini, S.D., Sujatha, V.(2013), Int J Pharm Pharm Sci.,5,70

8. King, A., Young, G.(1999), Journal of the American Dietetic Association, 24, 213.

9. Khan, A., Shah, R. D., and Pallewar, S.(2010), International Journal of Pharmacognosy and Phytochemical Research ,3, 22 .

10. Kumar, S. P., Sucheta, S., Sudarshana, V., Selvamani, P.(2008), African Journal of Biotechnology, 7,12.

11. Mukhtar, S., Ghori, I.(2012), International Journal of Applied Biology and Pharmaceutical Technology, 21, 31.

12. Mabry, T. J., Markham K. R. : Mass spectrometry of Flavonoids : In "The Flavonoids" John Willey and Sons,New York, pp. 78 (1975).

13. Pal, H.C., Sehar, I., Bhushan, S., Gupta, B.D., Saxena, A,K.(2010), Toxicology in vitro, 24,1599

14. Ravishankar, B., Shukla, V.J.(2007), African Journal of Traditional, Complementary and Alternative Medicines, 3,319.

15. Wikler, M. A., ed. "Performance Standards for Antimicrobial Susceptibility Testing: Seventeenth Informational Supplement, Clinical and Laboratory Standards Institute (2007). 